\title{
Drying characteristics of red chili in a swirling fluidized bed dryer: An experimental study
}

\author{
Mohd Azlan Zulkarnain, Nor Farhanim Md Rashid, and Ahmmad Shukrie Md Yudin* \\ Energy and Sustainability Focus Group, Faculty of Mechanical Engineering, Universiti Malaysia \\ Pahang, 26600, Pekan, Pahang, Malaysia
}

\begin{abstract}
Red chili is an agricultural product that contains high moisture. In this study, the drying process of red chili was conducted by using two methods which are conventional method of drying under the sun and by using swirling fluidized bed dryer. A fluidized bed column of $108 \mathrm{~mm}$ in diameter with slotted distributor of $45^{\circ}$ inclination angles was used in the experiment. Result of drying by using conventional method showed that for $1 \mathrm{~kg}$ of sample the drying time was 13 days with $212 \mathrm{~g}$ weight reduction and the color of the red chili changed from red to dark red. Meanwhile for swirling fluidized bed dryer the time required was 4 days, $200 \mathrm{~g}$ weight reduction and the color of red chili maintained. Based on the results obtained, the drying of red chili by using swirling fluidized bed dryer is more efficient as compared to drying by using conventional method.
\end{abstract}

\section{Introduction}

Drying involves the simultaneous application of heat and removal of moisture from the foods. The drying parameters needed are air temperature, relative humidity and air velocity based on nature of food and type of drying method. In the drying process, the generated hot air provides necessary heat to evaporate the moisture and carries it away from the products [1]. Generally, there were three types of method used for drying agricultural products. Firstly, drying process of chili by using conventional way of drying under the sunlight. The process start with the selection of good quality of red chili and then dry under sunlight for a couple of days at an open area until its moisture content become below than 5\%. In open sun drying, there is a considerable loss of product due to various reasons such as rodents, birds, insects and micro-organisms. The unexpected rain or storm further worsens the situation [2]. With the awareness of inadequacies involved in open sun drying, a more variation method of solar-energy utilization for crop drying has emerged as controlled solar drying [3]. The methods are using solar greenhouse drying system, indirect-type forced solar dryer system and double-pass solar dryer system [4-6].

\footnotetext{
${ }^{*}$ Corresponding author: shukrie@ump.edu.my
} 
Beside the conventional sun drying, the agricultural products were dried in a rotary drum dryer that utilizing microwave technology [7]. Drying for any agricultural product includes red chili can be done by using fluidized bed dryer (FBD). This FBD drying technology offers significant advantages of higher transfer rate for heat and mass between gas and solid that ensure a rapid and uniform drying [8]. However, stratified flow and hotspot formation in FBD dryers may lead to high moisture variation damage with considerable loss of quality to the product [1].

Following the successful development of inclined distributor that lead to a swirling air flow motion in a fluidized bed [9-10], attempt is made in the study to investigate the drying characteristics of red chili in a fluidized bed dryer using $45^{\circ}$ inclined distributor. The drying characteristics of red chili will be compared with the conventional drying under the sun.

\section{Experimental Set Up and Procedure}

The experiments were conducted by using Fluidized Bed setup as shown in Figure 1 (a). In order to scientifically investigate the performance characteristics of red chili in fluidized bed dryer, the following requirements are specified:

1. Fluidized bed system that allows interchangeability of the distributor.

2. Clear silica glass cylinder to enable visualization of studies.

The fluidization column consists of transparent cylindrical silica glass which has $108 \mathrm{~mm}$ internal diameter, $5 \mathrm{~mm}$ thickness and $310 \mathrm{~mm}$ length. A metal plate that has the same diameter with the glass column's flange was mounted at the bottom. The metal plate is connected to the air plenum's flange and act as distributor holder where $45^{\circ}$ inclination angle distributor was inserted Figure 1 (b). Fluidization air was supplied by low capacity of 1HP steel sirocco blower (VENZ ${ }^{\mathrm{TM}}$ model SC-362) with maximum flow rate capacity of $0.22 \mathrm{~m}^{3} / \mathrm{s} .45^{\circ}$ inclination angle distributor was used

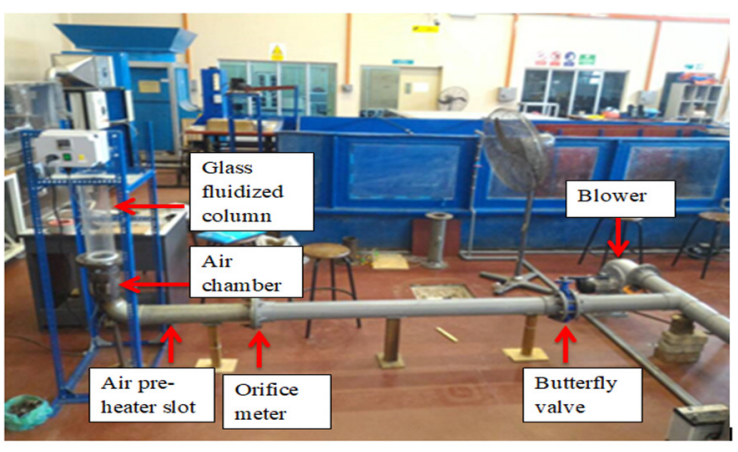

(a)

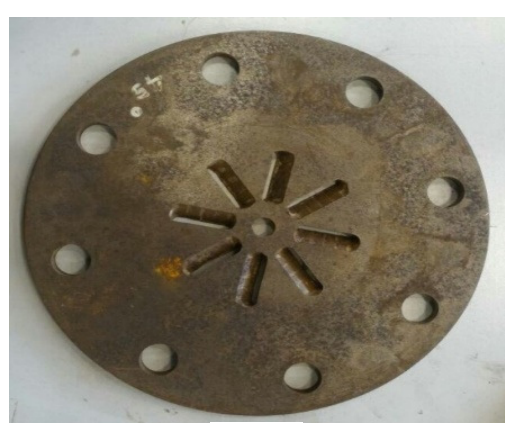

(b)

Fig. 1. Fluidized Bed Dryer Set Up (a) Photograph of the setup (b) $45^{\circ}$ angle distributor used in this experiment

\section{Methodology}

\subsection{Conventional Drying}

The experiment was conducted under sunlight at an open area. It is to investigate the drying time needed for drying process and moisture content after the drying. The figure of the 
experimental setup is shown in Fig. 2. The apparatus used for the experiment were drying mat, digital weighing scale and temperature data logger.

Approximately, $1 \mathrm{~kg}$ of sample was uniformly spread on a drying mat. Drying mat is basically from a wire mesh that being cut into small piece to place the chili on it so that the air surrounding can circulate around the red chili. The unit used for weighing scale was in gram and it used to measure the weight of chili before and after drying process. From the weighing process, moisture content can be calculated and also moisture ratio based from the percentage of moisture content by using formula.

The temperature data logger used to record the temperature of surrounding during the drying under the sun. There was a thermocouple that being attached to the drying mat and the temperature would be recorded throughout the experiment. From the temperature data recorded, the average value is used to plot the graph of moisture ratio and temperature vs drying time for each day of drying process.

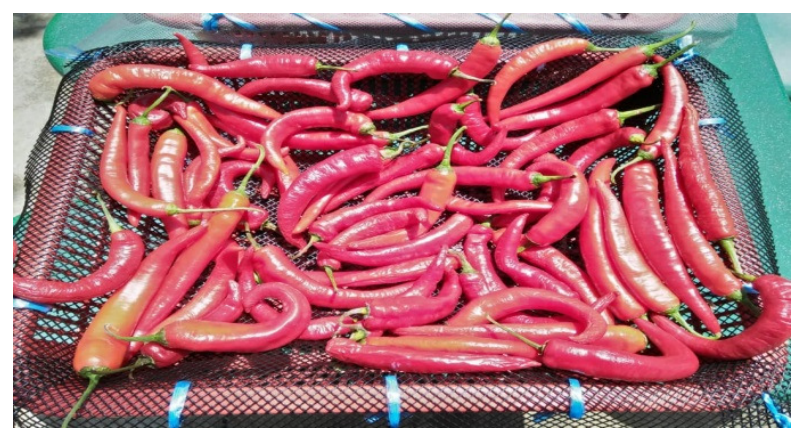

Fig. 2. Set up of the conventional drying

\subsection{Fluidized Bed Drying}

The experiment was conducted to investigate the performance characteristic of one distributor configuration ( $45^{\circ}$ angle). The figure of the experimental setup is shown in Fig. 3. Approximately, $1 \mathrm{~kg}$ of sample was placed in the fluidized bed column. Weighing scale also used in this experiment and the temperature data logger was attached near to the fluidized bed column so that the temperature of air inside the bed would be recorded. The fluidized bed dryer consists of four stages which are first level is packed regime where there is no movement inside the bed column. Second level, there are bottom and top layer, where the bottom layer is for swirling and top layer is for vibrating the products. Third level is partially swirled and lastly fully swirl.

The air is flow from blower, the electrical heater $(2.5 \mathrm{~kW})$ was on in order to supply heat during the drying process so that the heated air is passed through the air chamber and it will evaporate the moisture content from the red chili and will eventually dried. After that, the next step was same with conventional method which the weight of red chili was measured, the temperature was recorded throughout the experiment and also moisture content and moisture ratio being calculated. Lastly, the graph of moisture ratio and temperature vs drying time was plotted. The moisture ratio calculation was performed according to H. Darvishi [11]. 


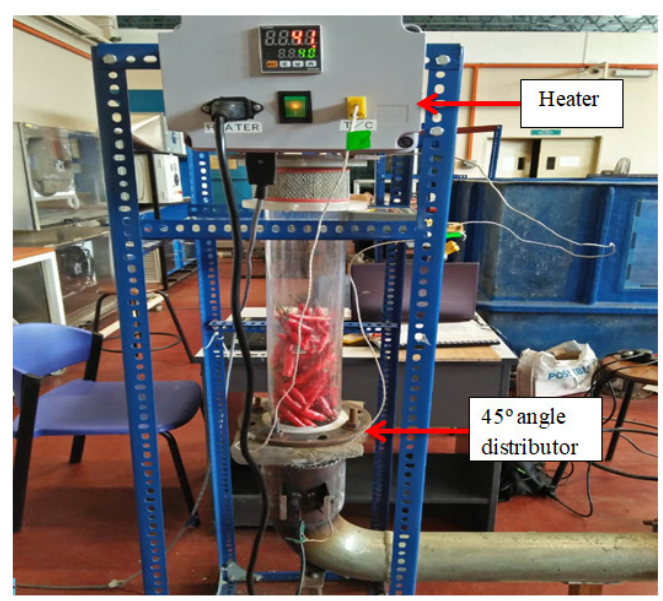

Fig. 3. Heater that connected to fluidized column

\section{Results and Discussion}

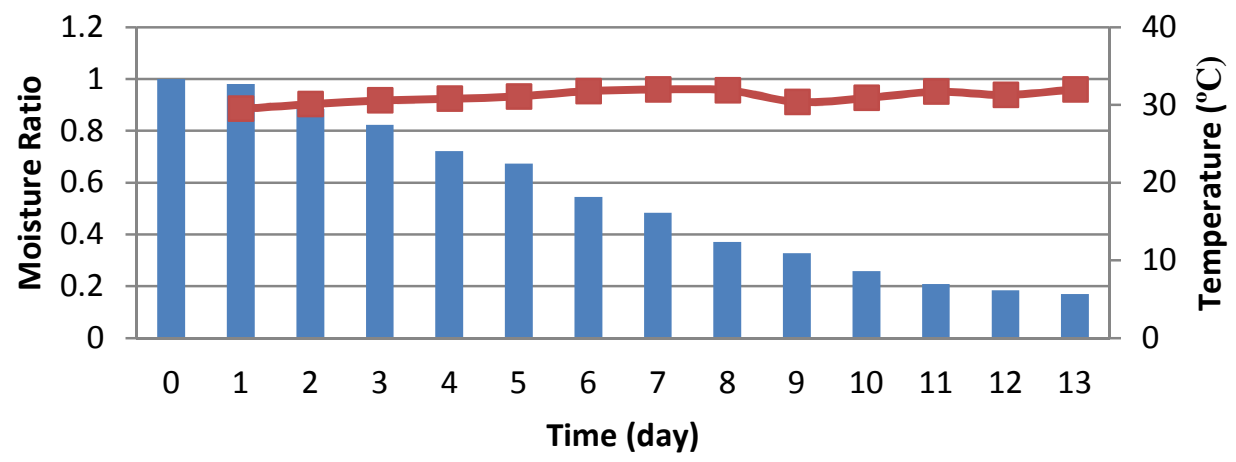

moisture ratio - temperature

Fig. 4. Graph of moisture ratio and temperature vs drying time for conventional drying under the sun 


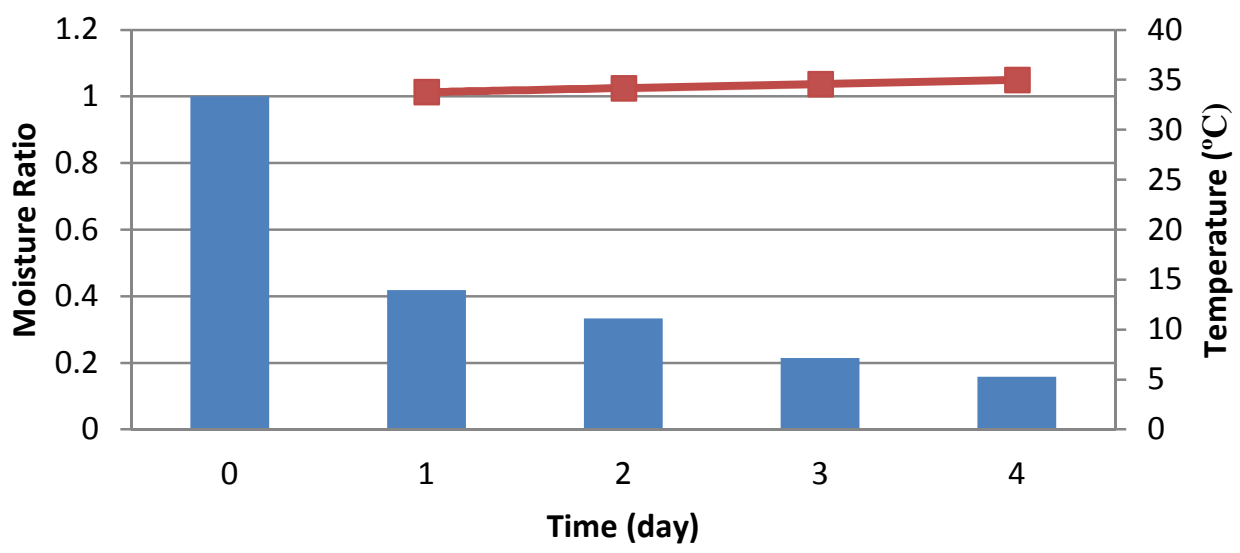

moisture ratio $\quad$ temperature

Fig. 5.Graph of moisture ratio and temperature vs drying time for drying by using Swirling Fluidized Bed Dryer

The drying characteristics of red chili have been experimentally studied both by conventional drying method and by swirling fluidized bed dryer. It can be concluded that for conventional method, the drying time required to dry red chilli took longer time which is 13 days for it to fully dried because the factor of weather need to be considered in order to conduct this experiment. However, drying by using fluidized bed dryer only took 4 days to evaporate the moisture content of the red chilli. It shows that fluidized bed dryer could save more time compared to conventional method. Besides, the percentage of moisture content for both methods was different. In conventional method, the red chilli have evaporated about $78 \%$ of moisture content right after it had been dried while for fluidized bed dryer around $80 \%$ of moisture content had lost from the red chilli throughout the experiment. This result had shown that the performance of fluidized bed dryer in drying the red chilli was more efficient compared to conventional method. The trend analysis for both conventional drying and swirling fluidized bed drying are plotted as shown in Figure 4 and Figure 5.

Furthermore, the visual characteristic of red chilli can be observed by using both methods. From the observation, conventional method had change the shape, colour and its quality as the red chilli was shrink and turned into dark red, and also it will affect the quality based on from the outside body of red chilli which did not interesting. However, in fluidized bed dryer, the condition of red chilli was maintained as the fluidized air that flow did not affect the shape and colour of red chilli and it will eventually effect on its quality.

Last but not least, it is proved that the performance of swirling fluidized bed dryer is more efficient in terms of save time, percentage of moisture content reduced and the quality is maintained compared to conventional method. Hence, the objectives for this project were achieved.

\section{Conclusion}

Swirling fluidized bed drying is proven experimentally to be more efficient than conventional drying for red chili. From the study, it has resulted that the characteristics of 
red chili by swirling fluidized bed drying is better than the conventional drying. The study can be improved by introducing different design of air distributors which can contribute to low pressure drop and improved particulate mixing in fluidized bed dryer. This swirling fluidized bed drying also can be extended to other agricultural products such as cocoa bean, black pepper, etc. which the has characteristics of low in moisture and feasible shape to be tested in the swirling fluidized bed dryer.

The authors wish to express their gratitude to the Faculty of Mechanical Engineering, Universiti Malaysia Pahang (UMP), Pekan, Pahang for providing the research facilities and supporting the research under University Research Grant RDU171110 and RDU180320

\section{References}

1. R. Sivakumar, R. Saravanan, A. Elaya Perumal, and S. Iniyan, Renew. Sustain. Energy Rev., vol. 61, pp. 280-301, (2016)

2. A. Sharma, C. R. Chen, and N. V. Lan, Renewable and Sustainable Energy Reviews, vol. 13, pp. 1185-1210, (2009)

3. G. Wisniewski, Drying Technology, vol. 15, pp. 2015-2024, (1997)

4. Z. Azaizia, S. Kooli, A. Elkhadraoui, I. Hamdi, and A. A. Guizani, Int. J. Hydrogen Energy, vol. 42, no. 13, pp. 8818-8826, (2017)

5. M. Castillo-Téllez, I. Pilatowsky-Figueroa, E. C. López-Vidaña, O. Sarracino-Martínez, and G. Hernández-Galvez, Appl. Therm. Eng., vol. 114, pp. 1137-1144, (2017)

6. J. Banout, P. Ehl, J. Havlik, B. Lojka, Z. Polesny, and V. Verner, Sol. Energy, vol. 85, no. 3, pp. 506-515, (2011)

7. W. Kaensup, S. Chutima, and S. Wongwises, Dry. Technol., vol. 20, no. 10, pp. 2067-2079, (2002)

8. S. Charmongkolpradit, K. Triratanasirichai, and N. Srihajong, Am. J. Appl. Sci., vol. 7, no. 10, pp. 1300-1304, (2010)

9. A. Shukrie, S. Anuar and A. Alias, Energy Procedia, vol. 75, pp. 1752-1757, (2016)

10. A. S. M. Yudin, S. Anuar, and A. N. Oumer, Adv. Powder Technol., vol. 27, no. 5, pp. $2102-$ 2111, (2016)

11. H. Darvishi, A. R. Asl, A. Asghari, M. Azadbakht, G. Najafi, and J. Khodaei, J. Saudi Soc. Agric. Sci., vol. 13, no. 2, pp. 130-138, (2014) 